\title{
Moisture Content Detection Based on Transmission Power Measurement Using a Microstrip Wide-Ring Sensor
}

\author{
Hou Kit Mun*1,a, Kok Yeow You ${ }^{2, b}$ and Mohamad Ngasri Dimon ${ }^{2, c}$ \\ ${ }^{1}$ Faculty of Engineering and Information Technology, Southern University College, 81300, Skudai, \\ Malaysia \\ ${ }^{2}$ Faculty of Electrical Engineering, Universiti Teknologi Malaysia, 81310 UTM, Skudai, Malaysia \\ *ahkmun@sc.edu.my, bkyyou@fke.utm.my, ${ }^{\mathrm{c}}$ ngasri@fke.utm.my
}

Keywords: Microstrip wide-ring, rice grain, moisture content, power, microwave technique.

Abstract. This paper proposes a microstrip wide-ring sensor for moisture content (MC) determination based on transmission power measurement. The microstrip wide-ring sensor with low insertion loss was designed to operate at frequency range from $1 \mathrm{GHz}$ to $3 \mathrm{GHz}$. Calibration equations for measurement of MC at $2.50 \mathrm{GHz}$ and $2.60 \mathrm{GHz}$ were obtained and validated with white rice for MC ranging from $10 \%$ to $28 \%$. The lowest error in MC prediction was $1.75 \%$ at $2.50 \mathrm{GHz}$.

\section{Introduction}

Moisture content (MC) of the rice grain is the most important criterion for quality assessment and process control. For instance, rice grain is usually harvested between MC $19 \%$ to $25 \%$ for maximum grain yield and needs to be dried to $14 \%$ or less, depending on the season and the weather, for safe storage [1]. Besides, the ideal MC for milling is $14 \%$ in order to maximize the head rice and minimize the broken grains. Thus, precise determination of the rice grain $\mathrm{MC}$ is important.

The conventional standard method for MC determination for grain is by using oven-drying method. Although this method can achieve high precision, it is time-consuming and impractical due to the sample required be dried 24 hours at a temperature at $130^{\circ} \mathrm{C}$. There are several applications reported that used microwave technique to sense grain $\mathrm{MC}$ such as a microwave microstrip ring resonator for single wheat grain [2] as well as prototype grain moisture meter using microwave transceiver [3], multi-layer microstrip moisture sensor [4] and cylindrical slot antennas for rice grain quality [5]. Among the microwave techniques, the microstrip ring offers many advantages. However, a typical microstrip ring with loose coupling will exhibit a high insertion loss of about $10 \mathrm{~dB}$ at the resonant frequency [6]. When a signal is transmitted through the microstrip ring with high insertion loss, the transmitted signal will become very low. Because of this very low transmission signal, some of the low cost measurement devices are unable to detect the transmitted signal.

This paper proposes a microstrip wide-ring sensor which is designed to operate within the frequency range from $1 \mathrm{GHz}$ to $3 \mathrm{GHz}$ and exhibits low insertion loss for $\mathrm{MC}$ determination. Besides, calibration equations of the sensor at selected frequencies are developed based on the relationship between the MC and measured transmitted power $P_{t}$. Moreover, wide-ring sensor operates at relatively low frequency within $1 \mathrm{GHz}$ to $3 \mathrm{GHz}$ can reduce the cost.

\section{Experiment and Methods}

The microstrip wide-ring sensor was designed using Microwave Office (MWO) for operation frequency range between $1 \mathrm{GHz}$ and $3 \mathrm{GHz}$, where its resonance frequency is located at $2.49 \mathrm{GHz}$. The sensor was fabricated on RT/Duroid 5880 substrate. The dimensions of sensor were sketched by using AutoCAD software and printed on transparent paper, then delineated on the substrate by standard photolithography and acid etching. Then, the sensor was held on an aluminum ground with two SubMiniature version A (SMA) connectors. Finally, the sensor was covered with acrylic holder as illustrated in Fig.1. The specifications of the substrate and dimensions of wide-ring sensor were tabulated in Table 1. 


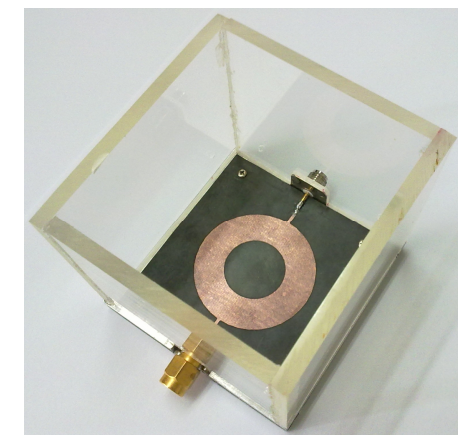

(a)

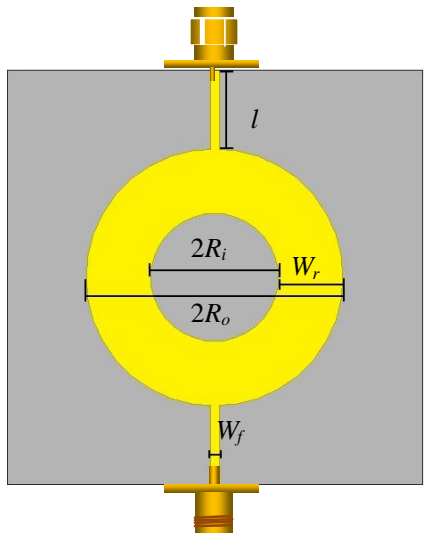

(b)

Fig. 1 (a) Actual configuration and (b) dimensions of the wide-ring sensor

Table 1. Substrate specifications and dimensions of wide-ring sensor

\begin{tabular}{c|c|c|c|c|c}
\hline \multirow{2}{*}{$\begin{array}{c}\text { Substrate } \\
\text { specifications }\end{array}$} & \multicolumn{5}{|c}{ Dimension $(\mathrm{mm})$} \\
\cline { 2 - 6 } & $W_{r}$ & $W_{f}$ & $R_{i}$ & $R_{o}$ & $l$ \\
\hline $\begin{array}{c}\varepsilon_{r, s u b}=2.2 \\
\tan \delta=0.001 \\
h=0.381 \mathrm{~mm}\end{array}$ & 9.03 & 1.14 & 8.92 & 17.96 & 11.09 \\
\hline
\end{tabular}

Jati $^{\mathrm{TM}}$ long grain white rice from Kedah, Malaysia was used as experiment sample. The average length, width and MC (wet basis) of the rice grain are $7.10 \mathrm{~mm}, 2.04 \mathrm{~mm}$ and 14\% respectively. For rice grain $\mathrm{MC}$ measurement, rice samples with a $\mathrm{MC}$ range of $10 \%$ to $28 \%$ were prepared. The rice grains were divided into different groups with 200 g per group. To cover the moisture range, some groups of grains were sprayed with different quantities of distilled water to achieve moisture levels ranging from $15 \%$ to $28 \%$, while other groups of grains were dried in a forced-convection oven for some period of time to cover the MC range of $10 \%$ to $13 \%$. The $\mathrm{MC}$ of each rice group was increased gradually from the lowest $\mathrm{MC}$ to the highest by increments of around $1 \%$. For each group, grains were stirred and sealed in a container at $4{ }^{\circ} \mathrm{C}$ for 72 hours to ensure uniform water distribution within the grains. The grains were conditioned to room temperature for 10 hours prior to the measurements. The actual MC of the grains was obtained by the standard oven-drying method. $10 \mathrm{~g}$ of each group was dried in a forced-convection oven at $130{ }^{\circ} \mathrm{C}$ for 24 hours [7]. The $\mathrm{MC}$ in percent was calculated on the wet basis as:

$$
\operatorname{MC}(\%)=\frac{m_{w}}{m_{w}+m_{d}} \times 100
$$

where $m_{w}$ and $m_{d}$ are the mass of water and dry grain respectively.

The sensor was connected to Vaunix LSG-602 Lab Brick signal generator and Mini-Circuit PWR-SEN-6G+ USB power sensor, both of which were controlled by a laptop computer. The power of signal generator was set to $5 \mathrm{dBm}$. Then, grain sample was placed into the sample holder of the sensor. The value of the measured $P_{t}$ is obtained from the software interface of the laptop. The measurement set-up is shown in Fig. 2. 


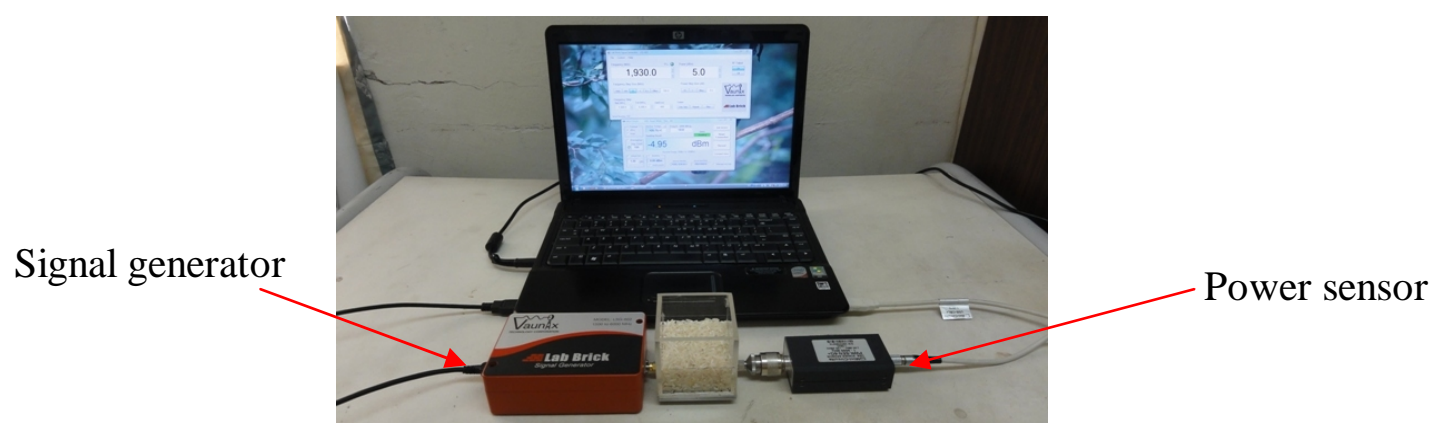

Fig. 2 Measurement set-up

\section{Results and Discussion}

Fig. 3 illustrates transmitted power as a function of frequency corresponding to different percentages MCs for wide-ring sensor. The measured $P_{t}$ corresponding to the MC range from $10 \%$ to $28 \%$ can be differentiated clearly within the sensitive frequency range.

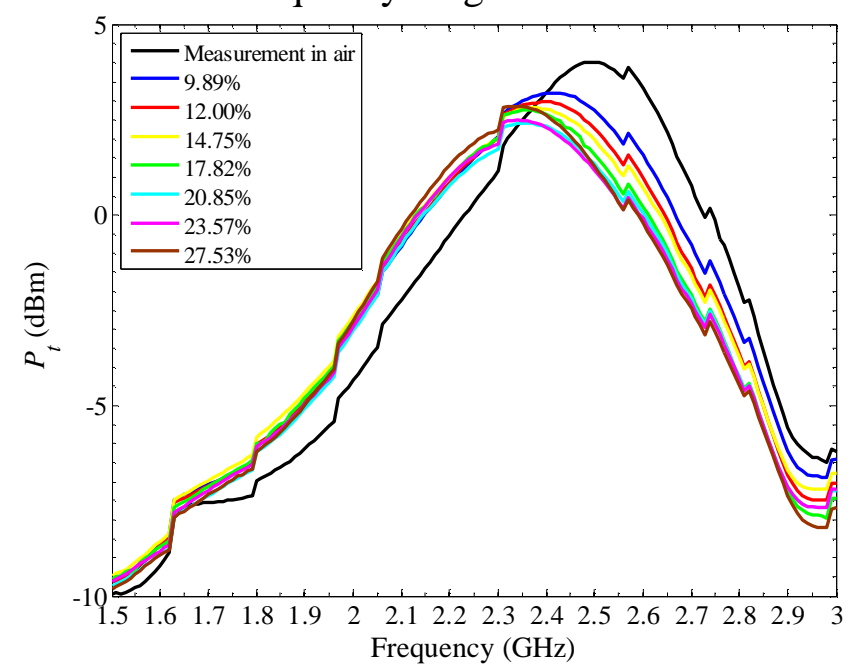

Fig. 3 Variation in transmitted power, $P_{t}$, with frequency corresponding to different MCs

Fig. 4 shows the calibration curves relating the different MCs with the corresponding $P_{t}$ at $2.50 \mathrm{GHz}$ and $2.60 \mathrm{GHz}$. The calibration equations based on the relationship between the MC with $P_{t}$ at selected frequencies are developed using 25 sets of rice samples by means of the regression analysis. The calibration equations and coefficient of determination $R^{2}$ are given in Table 2. The developed calibration equations can be used to predict the MC of each rice sample.

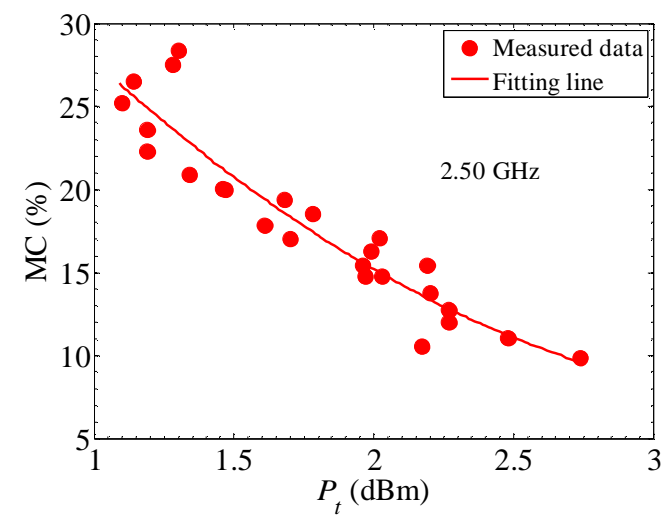

(a)

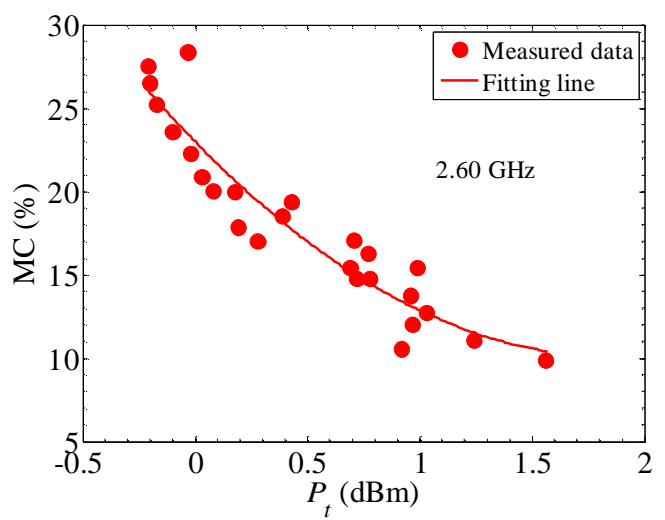

(b)

Fig. 4 Variation in MC with transmitted power $P_{t}$ at (a) $2.50 \mathrm{GHz}$ and (b) $2.60 \mathrm{GHz}$ 
Table 2 Calibration equation and coefficient of determination at $2.50 \mathrm{GHz}$ and $2.60 \mathrm{GHz}$

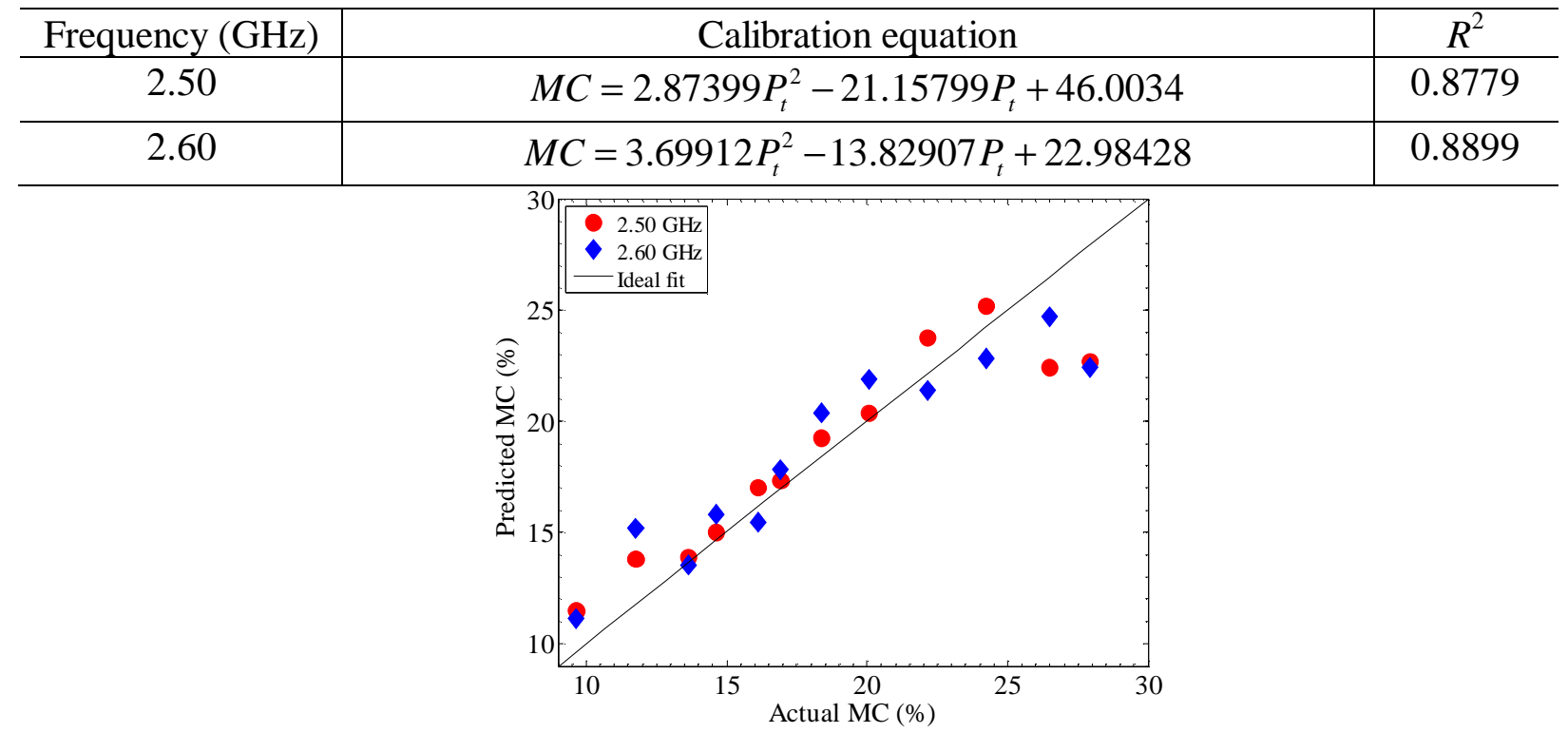

Fig. 5 Predicted MC against actual MC

A new set of rice samples with a MC of between $10 \%$ and $28 \%$ was prepared to validate the calibration equations. The predicted MCs are plotted against the MC calculated from Eq. 1 with the solid line representing the ideal fit as shown in Fig 5. The predicted values by calibration equation at $2.50 \mathrm{GHz}$ are closer to the line of ideal fit if compared with calibration equation at $2.60 \mathrm{GHz}$. The $R^{2}$ and average error in MC prediction for calibration equation at $2.50 \mathrm{GHz}$ are 0.8457 and $1.57 \%$ respectively, while for calibration equation at $2.60 \mathrm{GHz}$ are 0.8389 and $1.75 \%$ respectively. The calibration equation at $2.50 \mathrm{GHz}$ is the best for MC prediction with the highest $R^{2}$ value and the lowest average error.

\section{Conclusions}

In this paper, a microstrip wide-ring as a sensor for rice $\mathrm{MC}$ determination via power measurement has been presented. Calibration equations for the sensor have been established by using a relationship between MC and measured power. Validation tests have shown that the MC can be best predicted by sensor with average error of $1.75 \%$ at $2.50 \mathrm{GHz}$. The proposed sensor with its open structure and small in size provides low cost, fast, and non-destructive microwave measurement technique for MC determination.

\section{Acknowledgements}

The author wishes to thank Ruth Shepherd from Manchester Metropolitan University (MMU) and Professor Richard Lansmon Spear from Southern University College for their valuable suggestions and proof reading to improve the readability of this paper. This work is financed by the Southern University College Conference Fund (SUCCF) provided by the Southern University College.

\section{References}

[1] K. R. Bhattacharya, Rice Quality: A Guide to Rice Properties and Analysis, Woodhead Publishing, New Delhi, India (2011) 
[2] M. P. Abegaonkar, R. N. Karekar, and R. C. Aiyer, A Microwave Microstrip Ring Resonator as a Moisture Sensor for Biomaterials: Application to Wheat Grains, Measurement Science and Technology 10 (1999) 195-200

[3] K. -B. Kim, J. -H. Kim, S. S. Lee and S. H. Noh, Measurement of Grain Moisture Content Using Microwave Attenuation at $10.5 \mathrm{GHz}$ and Moisture Density, IEEE Transactions on Instrumentation and Measurement 51 (1) (2002) 1196-1200

[4] F. Jafari, K. Khalid, W. M. D. W. Yusoff and J. Hassan, The Analysis and Design of Multi-Layer Microstrip Moisture Sensor for Rice Grain, Biosystems Engineering 106 (3) (2010) 324-331

[5] K.Y. You, J. Salleh, Z. Abbas and L.L. You, "Cylindrical slot antennas for monitoring the quality of milled rice," in Progress in Electromagnetics Research Symposium, Suzhou, China, 12-16 September 2011, 1370-1373

[6] K. Chang and L. -H. Hsieh. Microwave Ring Circuits and Related Structures, 2nd ed., John Wiley \& Sons, Hoboken, New Jersey (2004)

[7] ASABE, ASAE S352.2 Moisture measurement - unground grain and seeds, American Society of Agricultural and Biological Engineers, Michigan (2006) 